\title{
Intramural esophageal dissection during peroral endoscopic myotomy
}

A 68-year-old woman with a history of aggravated dysphagia and regurgitation for 10 months was diagnosed with achalasia and was referred for peroral endoscopic myotomy (POEM) ( $\triangleright$ Video 1 ).

Preoperative esophagography showed a dilated esophagus without obvious passage of contrast agent. With the patient under general anesthesia, and after submucosal injections of saline with methylene blue, mucosal incision was performed at $10 \mathrm{~cm}$ above the gastroesophageal junction (EGJ) using a dual knife. During creation of the tunnel it was not possible to sufficiently lift the mucosa after repeated injections ( $>$ Fig. $\mathbf{1}$ ), and rupture of the mucosa was suspected ( Fig.2); however no mucosal breach was noted after repeated observations. An unusual-looking visual field was then exposed ( $>$ Fig.3), which looked totally different from the submucosal tunnel created later (\$ Fig.4). The lifting sign was achieved after injections to a deeper layer, and subsequent dissection of the deep layer confirmed that the unusual visual field was above the muscularis mucosae ( $\mathbf{F i g . 5}$ ). Therefore, a diagnosis of intramural esophageal dissection during POEM was made. Finally, the submucosal tunnel between the muscularis mucosae and muscularis propria was created uneventfully. Myotomy and mucosal entrance closure also went smoothly. There was no unexpected mucosal breach during the whole procedure.

The patient began to drink at postoperative day 1 , and was discharged from our hospital after 2 days. During 1 month of follow-up, the patient's symptoms improved significantly. Esophagography also confirmed the improvement of achalasia.

Intramural esophageal dissection is occasionally associated with oral anticoagulants, eating burnt or rough food, or vomiting during upper endoscopy [1]. As far as we know, intramural esophageal dissection occurring during POEM has not been reported, and it may be attributed to injection or inflation during the procedure. Since intramural esophageal dissection is superficial, an uneventful mucosal breach is more likely to occur. Early identification of intramural esophageal dissection during POEM helps in modifying the procedure, reducing the risk of complications such as postoperative infection.
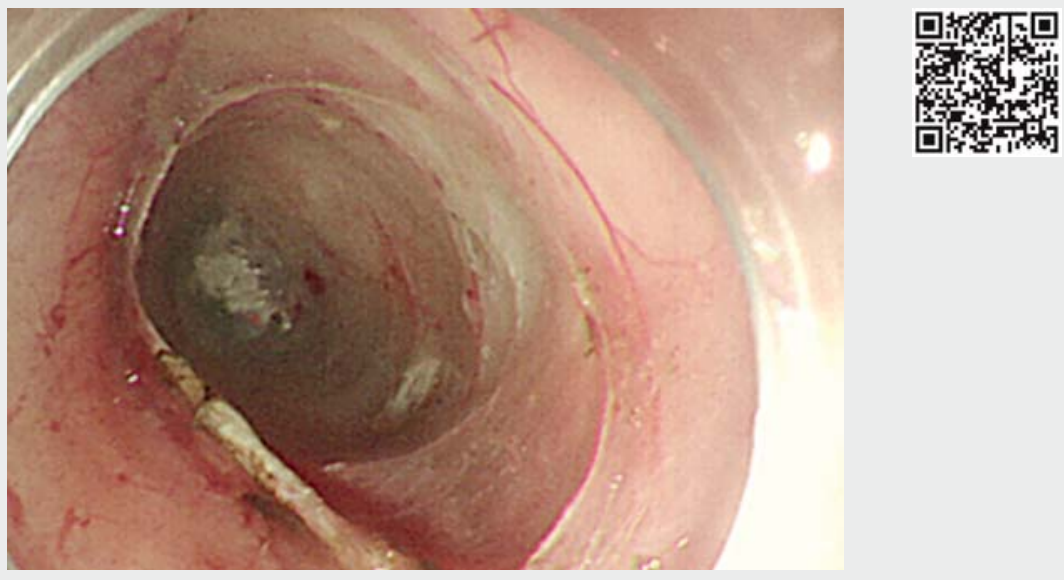

$\checkmark$ Video 1 Intramural esophageal dissection during peroral endoscopic myotomy.

Endoscopy_UCTN_Code_CPL_1AH_2AJ

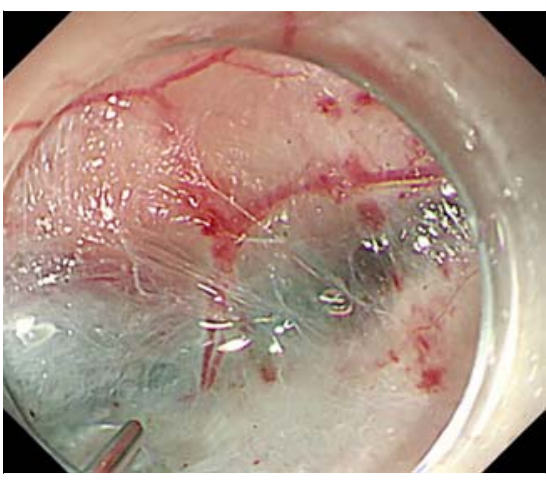

Fig. 1 During peroral endoscopic myotomy for achalasia in a 68-year-old woman, the lifting sign was not achieved after repeated injections at the beginning of tunnel creation.

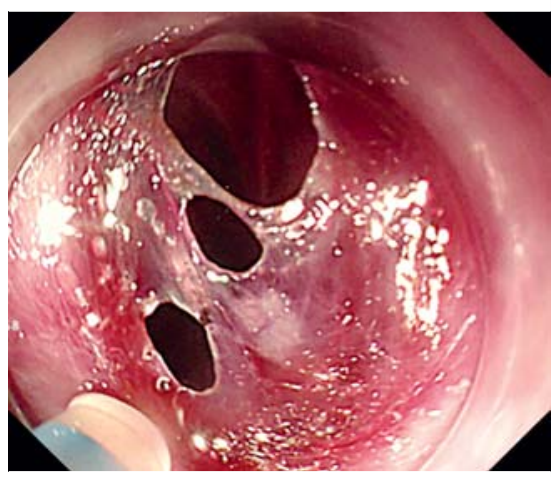

Fig. 2 Mucosal rupture was suspected during continuing creation of the tunnel.

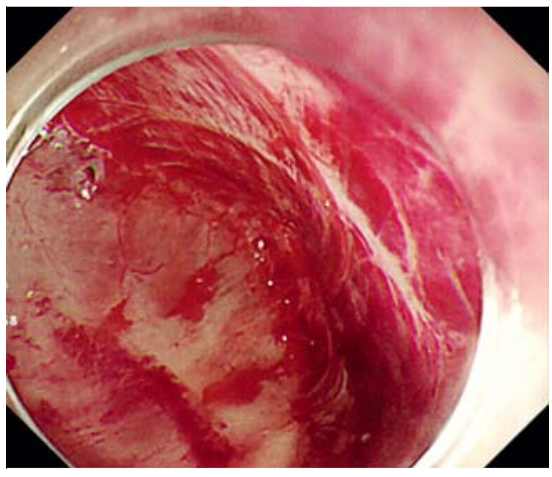

- Fig. 3 An unusual-looking visual field was seen after mucosal rupture. 


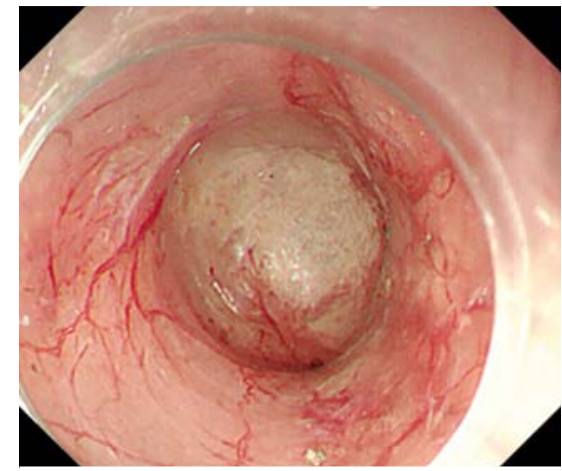

- Fig. 4 The submucosal tunnel created later in the procedure.

\section{Acknowledgment}

The authors acknowledge support from the Health and Family Planning Commission of Sichuan Province (16PJ275).

\section{Competing interests}

All authors disclose no conflicts of interest relevant to this article.

The authors

Liansong Ye1, ", Jingsun Jiang 2, ", Saowanee Ngamruengphong ${ }^{3}$, Wenjuan Yang', Linjie Guo', Yuhang Zhang ${ }^{1}$, Bing Hu${ }^{1}$

1 Department of Gastroenterology, West China Hospital, Sichuan University, Chengdu, Sichuan, China

2 Department of Clinical Research Management, West China Hospital, Sichuan University, Chengdu, Sichuan, China

3 Division of Gastroenterology and Hepatology, Johns Hopkins Medical Institution, Baltimore, Maryland, USA

\footnotetext{
${ }^{*}$ Co-first authors
}

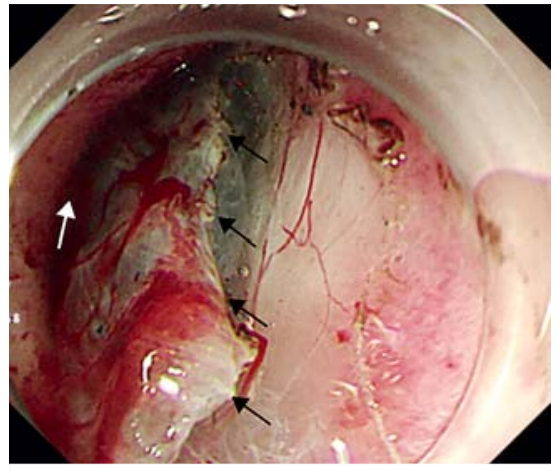

- Fig. 5 The area with the unusual appearance (white arrow) was above the muscularis mucosae (black arrows).

\section{Corresponding author}

\section{Bing Hu, MD}

Department of Gastroenterology, West China Hospital, Sichuan University, No. 37 Guo Xue Xiang, Wu Hou District, Chengdu, Sichuan 610041, China

Fax: +86-028-85423387

hubingnj@163.com

\section{Reference}

[1] Wang Q, Zeng H, Mou Y et al. Intramural esophageal dissection: a rare complication of upper gastrointestinal endoscopy. QJM 2016; 109: 71-72

\section{Bibliography}

DOI https://doi.org/10.1055/a-0875-3869

Published online: 12.4.2019

Endoscopy 2019; 51: E197-E198

(c) Georg Thieme Verlag KG

Stuttgart · New York

ISSN 0013-726X

\section{ENDOSCOPY E-VIDEOS \\ https://eref.thieme.de/e-videos}

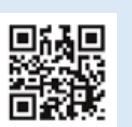

Endoscopy E-Videos is a free access online section, reporting on interesting cases and new

techniques in gastroenterological endoscopy. All papers include a high quality video and all contributions are freely accessible online.

This section has its own submission website at https://mc.manuscriptcentral.com/e-videos 